\title{
Heeding the Rebel Yell: Identification and Communication in Managing Organizational Issues
}

Received (in revised form): December 3, 2004

\section{McLean Collins}

McLean Collins is a graduate student in the institutional advancement program at Peabody College of Vanderbilt University. He is interested in the intersection of communication strategy and fund raising in higher education.

\begin{abstract}
In applying an issue development model, it is suggested that strategic identification and communication of the Colonel Reb issue would have helped the University of Mississippi to smoother transition to a new athletic mascot.
\end{abstract}

\section{Keywords: \\ crisis communication, issues management, identity, symbols}

\section{Introduction}

Crisis confrontation is a normal part of organizational development and growth. However, an organization that is proactive in scanning the environment is more likely to prevent those issues from developing into crises. Further, in order to successfully diffuse crises, the organization must have an effective issues management plan to identify those issues and begin to

Author's Contact Address:

McLean Collins

Institutional Advancement Program

Box 514-GPC

Peabody College

Nashville, TN 37203, USA

Phone: +1 7316947274

Email: john.m.collins@vanderbilt.edu communicate about them with various publics. This paper discusses and applies these models to an issue on a university campus. It starts by discussing the history of Ole Miss and traces the evolution of the Colonel Reb issue through the summer and fall of 2003. It then defines crises and issue development, and discusses the importance of a strategically planned issue identification and communication system.

\section{Background}

There is a valid distinction between The University and Ole Miss even though the separate threads are closely interwoven. The University is buildings, trees and people. Ole Miss is mood, emotion and personality. One is physical, and the other is spiritual. One is tangible, and the other intangible. The University is respected, but Ole Miss is loved. The University gives a diploma and regretfully terminates tenure, but one never graduates from Ole Miss. ${ }^{1}$

Vision, mission, and goals

The University of Mississippi was founded in 1848 as Mississippi's flagship university. In striving to be a great, 
comprehensive, public institution, the University's primary functions are the creation, dissemination, and application of knowledge through a variety of undergraduate, graduate, and professional programs and public service activities. In fulfilling its mission, the University is committed to teaching, research, service, and developing diverse campuses that recognize and promote the value of individual differences. The researchextensive, doctoral degree-granting University is composed of nine academic divisions on its main campus in Oxford: the College of Liberal Arts; the Schools of Accountancy, Applied Sciences, Business Administration, Education, Engineering, Pharmacy, and Law; and the Graduate School. The school's current enrollment is 14,500 students, with 13 percent of those students being African-American.

\section{University symbols}

The University of Mississippi was known only by that name until the first yearbook was published in 1896. The yearbook was called Ole Miss. The ambiguous name, which some suggest was a term slaves used to address the mistress of the plantation and others suggest was a reverence toward Mississippi, stuck to the university. The official school colors of the University of Mississippi were chosen as Red and Blue (from the crimson of Harvard and the blue of Yale). On the athletic fields, Ole Miss played under the colors of Red and Blue and the school nickname, the Flood, from 1896 until 1936, when a contest was announced in Oxford to rename the mascot of the university. That fall, 18 of 21 Southern sportswriters chose the Rebels as the new Ole Miss mascot.

A student represented the mascot from 1936 until 1978, by dressing in a Confederate soldier's uniform to motivate the team and cheer on the crowd at Ole
Miss sporting events. In 1979, the student was replaced by Colonel Rebel (affectionately known as Colonel Reb), a Disney-like mascot dressed in the attire of an eighteenth-century Southern gentleman. Confederate battle flags and the playing of "Dixie" were still common around campus sporting events, most noticeably at Ole Miss football games. However, in 1983, and after much debate, Ole Miss faculty and staff officially disassociated the school from the Confederate battle flag. In 1991, the Ole Miss Alumni Association followed suit.

While the flag was not officially associated with the university, many students and alumni continued to display it on campus and at Ole Miss sporting events. So, in 1997, the Ole Miss Student Senate adopted a resolution urging students to refrain from waving the Confederate flag at Ole Miss events. Students largely complied. The very same old-South relics, however, continued to stir debates around campus and the nation. This led Chancellor Robert Khayat to hire New York-based BursonMarsteller to perform a study on Colonel Reb and other symbols at Ole Miss in 1997. The purpose of the study was cited as the desire to strengthen the academic reputation of the university. Although much speculation circulated around Oxford for the next five years, in 2002, Chancellor Khayat finally spoke on the future of the Ole Miss symbols: "We are and will be Ole Miss. We are and will be the Rebels. We do and will continue to play "Dixie." Colonel Reb will be the mascot.",

\section{Colonel Reb}

While Colonel Rebel the athletic mascot was introduced in 1979, his image had appeared in Ole Miss yearbooks and on Ole Miss merchandise since 1938. In fact, 
it was this image that motivated the new athletic mascot design of the eighteenthcentury cartoon gentleman that would replace the Confederate-dressed student on the sidelines. Not much was made of the mascot until 1997, when Chancellor Khayat hired a firm to examine these symbols and their effects. Yet, much speculation and five years later, Chancellor Khayat quelled fears by assuring the Ole Miss community that the Rebel nickname, along with Colonel Reb, was there to stay. Needless to say, the announcement that Colonel Reb would be removed and replaced as the Ole Miss athletic mascot came as quite a shock to the university community. The following describes the development of the Colonel Reb issue from May 19, 2003 until October 10, 2003 (see also Timeline 1).

On May 19, 2003, Sports Illustrated picks up an AP story that Ole Miss Athletic Director, Pete Boone, has announced that Colonel Reb, the university's beloved mascot, should no longer represent sports teams at the university. It is another month before Boone releases further comment on the removal of Colonel Reb, confirming that the mascot will not be on the sidelines for the 2003 football season, but assuring fans that he will still be in the Grove before games. ${ }^{3}$ In this article, Boone claims there has been talk of discarding Colonel Reb from the athletic department for eight years. The article also interviews the Ole Miss Assistant Vice Chancellor of University Relations, Jeff Alford, who claims to know nothing of the removal. Later that day, the university newspaper, the Daily Mississippian, releases an editorial criticizing the administration's stiff stance, vague arguments, and closed-mouth policy regarding the future of Colonel Reb. The following day, about a month after the initial news-break, Chancellor Khayat finally speaks, reporting that Colonel Reb is still an official symbol of the university, distinguishing the removal of Colonel

Reb from the sidelines as an athletic issue. It is decided that a contest will be held to find a replacement for Colonel Reb.

On June 23, rumors begin to circulate regarding the reasons for the ousting of Colonel Reb. The recruitment of student athletes is mentioned, speculating that Colonel Reb may be associated with racism, slavery, and the subjugation of blacks. In response to the rumors, Chancellor Khayat releases a statement claiming that race has absolutely no part in the decision. Two weeks later university alumni begin to voice their opinions on web logs and message boards-most are negative, citing the handling of the issue, more than the issue itself, as the cause for concern. Many threaten to boycott sporting events. However, season tickets for the 2003 football season remain on pace with 2002.

The issue is silent until July 30 , when Pete Boone announces a nationwide contest to replace Colonel Reb. The winner will receive a $\$ 5,000$ cash prize and will be revealed in late September. Meanwhile, the Ole Miss football season begins on August 30, 2003 at Vanderbilt University, with Colonel Reb absent from the sidelines. In late September, eligible alumni, students, faculty, and staff can vote for one of the two final optionsRowdy Rebel or Rebel Bruiser. However, neither seems to be popular with fans.

Contrary to previous statements, Pete

Boone releases a statement to the Commercial Appeal on October 6, 2003, citing that the mascot was and is hurting recruitment. He says that he has seen two letters from other coaches written to athletes that the university are trying to recruit, trying to play the mascot issue against them. The letters refer to the racial 
implications of Ole Miss symbols and Colonel Reb. Afterward, Ole Miss fans begin to revisit the original reasons behind the removal of Colonel Reb. Regardless, on 10 October, after nearly five months of debate and discussion, the University of Mississippi ends its search for a new mascot unsuccessfully, citing a lack of interest in the two proposed mascots. Only 2,400 out of 40,000 eligible Ole Miss constituents vote. "The matter is closed," states Chancellor Robert Khayat. $^{4}$

\section{Varying interpretations of the Colonel Reb issue}

In the fall of 2003 it was certain that Colonel Reb would no longer be on the Ole Miss sidelines. Yet that was perhaps the only certainty that the University of Mississippi administration, faculty, staff, and students could claim. While the issue of Colonel Reb's presence on the sidelines was settled, the interpretations and opinions on the issue from university constituents' were numerous, passionate, and diverse. What follows is a description of group sentiments based on newspaper articles, editorials, and opinion pieces dated May 19, 2003 through October 10, 2003.

\section{Administration}

The initial newswire of May 19, 2003 was released solely from the athletic department, with no coordination with any other university offices. It must be noted, therefore, that other departments were not consulted on or informed of this decision. The claim is supported with statements made by Chancellor Khayat and Assistant Vice Chancellor of University Relations Jeff Alford, in which they both attributed the decision to Pete Boone. "I'm not real sure what the future of Colonel Reb is right now," says Khayat in the Daily Mississippian. Alford comments, "This is coming straight from the athletic department. I don't know what kind of effect it is going to have, if any." 5

Boone initially announced that the reason for the change was that "it [Colonel Reb] doesn't fit anything we do," citing the need for a "champion's image" to represent the University of Mississippi athletics. ${ }^{6}$ One month later Boone attempts to clear up confusion by announcing that Colonel Reb will still be in the Grove before games, just not on the sidelines. In conjunction with this, Chancellor Khayat announces that Colonel Reb is still an "official symbol" of the university. ${ }^{7}$ As of June, 2003, they both claim that race has no influence on the decision.

Students, alumni, atbletic supporters Students are away from campus for the summer during the decision. Some of the students still on campus include a few staff writers working for the Daily Mississippian. While views on the elimination of Colonel Reb as an athletic mascot vary, some students and alumni are indifferent, or support the decision. Charlie Waite, a senior catcher for the baseball teams says, "I do not see anything wrong with updating the mascot we already have. If they change the mascot completely, that would be kind of a weird deal ... my grandmother in California knows Ole Miss by the mascot." Rick Rogers, a senior from Huntsville says, "Personally, I like our mascot, and I do not view it from a negative side. But if it does have a negative connotation for someone, I think it should be changed."9 The Black Student Union also issues a press release stating, "We, the Black Student Union, agree that Colonel Reb should be changed to promote the 
progress of our University, our state and our nation [and] should reflect common ideals, goals, and the fighting spirit that has made our state a better place to live."10

While some students support the decision, there are also many students and alumni who disagree with the removal of Colonel Reb. One alumnus expresses, "The Colonel Rebel decision has changed my mind about going to Ole Miss football games this year." "Another young alumnus conveys, "I did plan to contribute [financially] ... but I do not now." 12 Many message boards and editorial pages begin to fill with criticisms of political correctness, and even some derogatory racial slurs. The majority (and the most offensive) of these, however, do not appear to be written by Ole Miss students.

Two common themes emerge from the analysis of those stories discussed above. First, students, alumni, supporters, and even other members of the administration seem to be confused as to the motive behind Colonel Reb being removed from the sidelines. Many supporters and denouncers claim race and political correctness, although few official comments ever discuss, debate, or appear to know about the race issue. Many constituents find Pete Boone's statements about Colonel Reb not being an "athletic mascot" or appearing as a "champion's image," vague and elusive. Secondly, whether students, alumni, and athletic supporters agree or disagree with the removal of Colonel Reb, the main frustration from all parties seems to be the approach and actions of the administration in handling this issue. A June 19 editorial in the Daily Mississippian lambastes the administration for sending uncoordinated, confusing messages to the university community. The Editorial Board writes:
What really turns the screws is how these actions were performed strictly behind closed doors, hidden by those administrators apparently afraid to phase a mascot out openly and honestly. If one truly believes that what he does is right, he should stand up for himself and not allow Colonel Reb mongers to verbally abuse his secretary via telephone ... he should conduct public press meetings to invite the input of fans ... [perhaps] rallying together some people who might otherwise support the AD's cause. ${ }^{13}$

An alumnus expresses similar sentiments, "I do not regret my purchase of this year's season tickets. ... However, I am very upset at the spineless manner in which the administration has handled the Colonel Reb affair."14 Ultimately, it seems that the majority of criticism from both students and alumni is directed at the way the issue was handled, rather than the reason behind the issue.

\section{Summary and analysis}

While the administration claimed that Colonel Reb has been removed to be refreshed or replaced with a new athletic identity, many students, alumni, and athletic supporters were confused and questioned the process behind the decision. From analyzing the development of the issue in the newspapers, the administration sent mixed signals, exhibited a lack of coordination, and surrounded itself in an air of secrecy with the announcement that Colonel Rebel would no longer be on the sidelines. More strikingly, university administrators failed to include any constituent groups (in this case, students, alumni, or supporters) in the decision. Finally, beyond isolating many important and 
influential constituents and relationships, the university failed to produce both a satisfactory replacement for Colonel Reb and a satisfactory explanation of why Colonel Reb would be removed from the sidelines but would remain a university symbol. As a result, most of the university constituencies seemed to feel isolated and offended, as if they had somehow been excluded from a participating relationship in an organization with which they so closely identified.

\section{Crisis Issue and Development}

This section of the paper analyzes the Colonel Reb issue within a crisis and issue development framework, discussing how the University of Mississippi could have more effectively planned and managed the issue by utilizing an issue development model. Theoretical models and definitions are presented, and how they could be applied to the Colonel Reb issue is outlined. This analysis and suggestive action includes three steps. The first involves analyzing and assessing Colonel Reb through a crisis and issue management framework. The second step involves understanding the components and nature of the issue. The third step describes how the university should manage and present the issue, including suggestions for approaching and interacting with various publics.

\section{Crisis model and classification}

Most universities have been or will be faced with a crisis. It is important, therefore, for institutions to know how to effectively classify and manage different types of crises. It is also important for an organization to be able to distinguish between crises and issues, and to know the skills necessary to manage each effectively.
Pauchant and Mitroff define a crisis as a disruption that affects a system as a whole and threatens its basic assumptions, subjective sense of self, and existential core. ${ }^{15}$ Seeger writes that organizational crises are rich with significance, drama, stress, and intensity. ${ }^{16}$ While these crises have conventionally been conceived of as the source of organizational confusion and chaos, Seeger also suggests that crises are a natural phase of organizational development. ${ }^{17}$ If this is true, then crises are not merely isolated incidents that affect an organization, but are instead part of a developmental cycle.

According to Gonzalez-Herrero and Pratt, the crisis life cycle is composed of birth, growth, maturity, and decline. ${ }^{18}$ It is important to remember, though, that not all crises are alike, and hence will not have identical characteristics on the crisis lifecycle. Crises vary in their magnitude and severity. Responses to crises also will vary. It is essential, then, to be able to identify and understand the type of crises in order to create and execute the appropriate responses for organizational development.

Burnett classifies types of crises by time pressure, control, threat-level concerns, and response option constraints. ${ }^{19}$ Time pressure can be characterized as intense or minimal; control by degree (low or high); threat level is characterized by low or high; and response options are determined as few or many. In Burnett's crisis classification matrix, a situation with a high degree of control, minimal time pressure, low threat level, and many response options would be considered a low threat, low priority issue, while a situation with a low degree of control, intense time pressure, high threat level, and few response options would be considered a high threat, high priority issue. ${ }^{20}$ Classifying crises can provide 
numerous organizational benefits. The crisis-classifying matrix helps to organize and display the problems that should be confronted, to provide a basis to rank and establish priorities, and to aid in the deployment of resources toward those priorities. So, after classifying the particular nature of the crisis, strategic management and response may be planned accordingly.

\section{Issues management}

\section{If crises are a normal part of} organizational development, then organizations would benefit from scanning for these crises before they ever formally arise. Seeger claims that issues management may be considered a proactive approach to organizational crises. ${ }^{21}$ In order to apply this approach, one must first define and understand its components. Seeger defines an issue as "a contestable claim about a matter of fact, policy, or values." 22 Dutton and Dukerich define issues as events, developments and trends that organizational members may recognize as having some affect on or consequence to the organization. ${ }^{23}$ These issues can arise from changes external or internal to the organization.

Issues management concerns itself with identifying and communicating about various issues, including monitoring internal and external trends such as those of key publics and constituents. ${ }^{24}$ Gonzalez-Herrero and Pratt add that issues management includes scanning the environment, collecting data, and developing a communication strategy. ${ }^{25}$ Therefore, effective issues management can help organizations to avoid crises by allowing the organization to take a proactive approach in scanning for potentially problematic issues and then planning and taking appropriate action to control those issues.

\section{Application}

Over the last 30 years, the University of Mississippi had dealt with crises related to university symbols such as the Confederate battle flag and playing of "Dixie." Many of these crises revolved around the different perception of the symbols by various university constituents. While many students and alumni saw these as representing the history of the school they knew and loved, some students and alumni saw them as representing a more oppressive, less progressive attitude within a public institution of higher learning. True, these problems would have probably been classified as low threat on the crisis matrix, but they still plagued the university in portraying an image that many administrators and some constituents did not feel truly represented the university. Similarly, while Colonel Reb was certainly no crisis, the matter did represent a contestable claim about a matter of "fact, value, or policy" and was therefore considered a relevant issue for the university. Its importance and relevance to the university is further noted by the university investing $\$ 30,000$ to study the mascot and determine the potentially negative effect that it, as well as other symbols, was having on the University of Mississippi.

According to many university and external sources, the evaluation of Colonel Reb had been on the radar for the last eight to ten years, due to the perceived negative effects on the academic prestige and image of the university. Finally, in May of 2003, Athletic Director Pete Boone and the athletic department had decided that Colonel Reb no longer "represented anything we (in athletics) do." 26 While the university would keep the Rebel nickname, they would search for a more energetic and appropriate 
mascot. Colonel Reb would still parade through the Grove before football games, and would still be an officially registered trademark of the university. He would not, however, represent or accompany the Rebels in the sports arena. End of story, case closed.

After the announcement that Colonel Reb would no longer represent the Ole Miss Rebels at sporting events, most constituents were confused, and many were unhappy. To most Ole Miss constituents, this issue was not just about "athletic representation," and was not isolated from other, similar issues in the institution's past. Because of the debates over previous university symbols, such as the Confederate battle flag and "Dixie," and the fact that the university had undertaken another symbol analysis in 1997, many alumni, students, and supporters were not buying the athletic argument. Hence, speculation and rumors began to arise as to why the university was taking such action, and what that action meant to the future of the university. Beyond not being coordinated, the university administration never seemed to engage in an effective dialogue with various publics, or produce any satisfactory answers to the questions of those publics.

The university administration (particularly Pete Boone) concluded that Colonel Reb no longer served the needs of the athletic department, and therefore removed the mascot. What the university failed to do, however, was to understand the issue from multiple perspectives, specifically researching and brainstorming how the university public regarded the issue, and how these constituents would react to the decision made on the issue (to remove and replace Colonel Reb). So, in examining how the university could have better managed the issue, we must discuss the importance of communication in an issue management framework.

\section{Communication}

After the issue has been identified, the communication process must be planned and executed. There are two parts to communication in the issues management process: information gathering and information promotion.

\section{Information gathering}

\section{Segmenting publics}

The first steps of information gathering are segmenting the market, clearly identifying different groups that merit attention, and understanding their orientations toward the particular issue. ${ }^{27}$ Publics can be understood as groups who have formed their own collective identity in relation to the organization.

Segmenting publics by their orientation towards the issue is important because it allows the organization to see the range and elements of those opinions. ${ }^{28}$ According to Vasquez and Taylor, the organization must understand the various public opinions (and symbolic realities) in order to understand various perspectives on the issue, and communicate accordingly. ${ }^{29}$ This process is beneficial to the organization in formulating strategies to send the appropriate messages to satisfy the different communication needs of the various segmented publics depending on the various constructed identities of those publics.

\section{Member and organizational identity}

Studying the relationship between individual and organizational identity is important in understanding how to gather research about and communicate with various publics. According to Dutton and 
Dukerich, “an organization's identity and image are critical constructs for understanding the relationship between actions on and interpretations of an issue over time." ${ }^{30}$ Albert and Whetten define identity as what organizational members believe to be its central, enduring, and distinctive character. ${ }^{31}$ In a study conducted on the Port Authority of New Jersey, Dutton and Dukerich found that the relationship between individuals' senses of their organizational identity and their own sense of who they are and what they stand for suggests that individual members have a stake in directing organizational action in ways they believe are consistent with what they believe is the essence of their organization. ${ }^{32}$ Therefore, changing or modifying anything that represents the organization (such as organizational symbols) will affect member attitudes and opinions, as well as affecting orientation of the member in relation to the organization.

\section{Symbols}

Symbols play a significant role in institutional identity, especially within a university. According to Connolly, symbols such as nicknames, colors, and mascots represent shared values and assumptions that foster group affiliation. ${ }^{33}$ Further, while originally intended for specific purposes (such as representation of athletic teams), these symbols may be one of the few things at a heterogeneous university that foster group and organizational identity. To many constituent groups such as alumni, students, and supporters, team nicknames, colors, and mascots represent longstanding traditions and history. Organizational symbols, therefore, are directly related to member identification with (and within) an organization.
Multiple and competing frames

Market psychology can be usefully applied when discussing the constructs of identity. According to Spiegel, "In market psychology, reality does not consist in the objective nature of a product, but solely in the consumers' perception., ${ }^{34}$ Similarly, organizational identity is a construct held in organizational members' minds. ${ }^{35}$

Many members with many different mental constructs of identity can, in turn, lead to a high degree of inconsistency, disagreement, and ambiguity in how organizational members interpret strategic issues. Dutton and Dukerich note that when organizations take actions that members see as inconsistent with its identity, members judge the issue as more important and the organization as more committed to the issue, which can lead to a greater sense of member support, or in some cases, a greater sense of member dismay or alienation. ${ }^{36}$ The same theory may be applied to action taken in regard to organizational symbols. So, when dealing with an issue of a university symbol, it is important to research and understand that issue from the many different member frames of reference within and external to the organization.

\section{Information promotion}

After information has been gathered, the organization must plan and execute a strategy to make the perspective of organizational frames known to and understood by key publics. The organization must then align the identity and frames of the members with that of the organization through communication. Leitch and Neilson indicate two main approaches to communication in the public relations field: the strategic approach where publics are portrayed as targets of organizational messages, and the dialogic approach where publics are 
portrayed as active and equal participants with the organization. ${ }^{37}$ Managing an issue may require a more systematic approach to maximize the support of publics and minimize opposition to achieve organizational objectives, while still engaging the constituents in an organizational dialogue.

Vasquez describes public relations as negotiation that focuses on the framing and reframing of issues. Vasquez's model of public relations as negotiation is based around the belief that parties may hold, or appear to hold, incompatible goals or interests (in this case, in relation to the identity of the organization). In other words, while both the university and the constituents are part of a shared mission or dialogue, two sides do not have equal input on the organizational issue. ${ }^{38}$

Instead, a negotiation approach communicates by using its power to try to reframe organizational goals to the constituents based on the research gathered about constituent beliefs and identities. In this approach, the organization may use its power to work towards shaping and aligning individual identity or belief with that of the organization. This is still a process, however, that encourages constituent participation and involvement.

Information gathering has engaged the constituents, and now organizational power will be used to assimilate the information gathered and strategize to facilitate the creation of frames of reference that support particular interpretations of and responses to their objectives. According to Leitch and Nielson, if the organization can establish a particular frame of reference for its publics, then it also may create favorable zones of meaning between itself and these publics. The result probably will be an environment where an organization is more likely to achieve its objectives. ${ }^{39}$

Tim Lepzring, a professor of higher education at the University of Mississippi, best sums up the steps in (and problems that can arise from) issue management in an article in the Commercial Appeal:

Change hasn't come easy and wasn't bound to. In other words, anything that has people's hearts-and Colonel Reb has people's hearts-making that type of change is difficult. Ideally, university officials had to convince all involved that changing Colonel Reb was the right thing to do. The administration believed this was the right thing to do, but didn't convince the constituents that this was the right thing to do. [When that doesn't happen], there's always some unintended consequences you just didn't see. ${ }^{40}$

\section{Suggestion}

In order to have effectively managed the issue of Colonel Reb, the University of Mississippi should have focused more on the communication process in general, and information gathering and promotion, in particular. The university should have utilized its public relations department to actively engage in communication with various constituent groups. From there, the administration could have calculated the range of opinions on the issue, and segmented publics to approach accordingly. Specifically, they could have identified and gathered those who were in favor of the change to communicate within their various public groups to advocate the university cause. Finding a prominent alumnus (or group of alumni) who sided with the administration would display administration and public interaction, and 
also provide the administration with some much needed support and credibility.

Conversely, engaging with those who were adamantly opposed to the issue would have given the university a chance to research that public's particular arguments, and engage and explain why those arguments may or may not be accurate. Regardless of the difference in opinions, all publics will be better equipped to engage in conversation and negotiation when they understand the specific reasons behind and evolution of the issue, and when the administration is coordinated in communication efforts regarding that particular issue.

Further, when discussing an alteration or removal of an organizational symbol, Connolly notes that gathering and disseminating historical information is crucial to sustaining a change process. $\mathrm{He}$ further indicates that a negotiated approach may help members surrender shared symbols while giving them time to adapt to changes. ${ }^{41}$ Beyond hiring a consulting firm to analyze the university symbols, the administration (and public relations department) should have conducted internal symbolic investigations targeting group members to explore the potential for multiple or competing meanings in order to better understand and reframe the perception of organizational identity to all participating groups and organizational members. The university could have then worked to separate and distinguish the essence of Ole Miss from a cartoonish eighteenth-century mascot. This publicity would also have provided a unique window of opportunity for the university to discuss, redefine, and promote the image of the organization to the university community. If this was done effectively, the university constituents would be encouraged to see farther beyond their own frame of reference, and the university could have worked to align and arrange these various frames within the overarching mission of the organization.

Ultimately, the University of Mississippi should work to align their actions and publicize their intentions in context of the organizational identity in order to show how the issue will affect the organization and the members, and what future implications or impact this issue will have. Although the decision regarding the Colonel Reb issue may have been made by the administration at the University of Mississippi (and the publics may not have equal participation in this decision), by segmenting, engaging, and communicating with those various publics the university would have had a better chance to reframe the issue and accomplish organizational objectives with as little interference and disturbance to the mission of the institution as possible. If this had occurred, there would likely be few claims of the university "closed-door policy" that were released by the students and alumni a few months after the decision was made to remove Colonel Reb from the playing field. Although the constituents may not all be delighted with the decision, they would still feel like important members of the university community, and would be more likely to communicate with the university on future issues.

\section{Summary}

Most universities have been or will be faced with a crisis at some point in their development. It is important, therefore, for these institutions to know how to effectively classify and manage different types of crises. Issues management concerns itself with identifying and communicating about various issues, including monitoring trends such as those of key publics. ${ }^{42}$ Effective issues 
management can help organizations avoid crises by allowing the organization to be proactive in scanning for potentially problematic issues.

After the issues have been identified, the communication process beings. This process is composed of two parts: information gathering and information promotion. The first step of information gathering is segmenting the market. ${ }^{43}$ This is beneficial to the organization in formulating strategies to send the appropriate messages to satisfy the public's different communication needs.

According to Dutton and Dukerich, organizational identity is a critical construct for understanding an issue. Therefore, changing or modifying anything that represents the organization (such as organizational symbols) will affect member attitudes and opinions, as well as affecting orientation of the member in relation to the organization. Many members with many different mental constructs of identity can, in turn, lead to a high degree of inconsistency, disagreement, and ambiguity in how organizational members interpret strategic issues. So, when dealing with an issue of a university symbol, it is important to research and understand the issue from the many different member frames of reference within and external to the organization. After information has been gathered, the organization must plan and execute a strategy to make the perspective of organizational frames known to and understood by key publics. The organization must then align the identity and frames of the members with that of the organization through communication. $^{44}$

A negotiation approach communicates by using its power to try to reframe organizational goals to the constituents based on the research gathered about constituent beliefs and identities. In this approach, the organization may use its power to work towards shaping and aligning individual identity or belief with that of the organization. The result probably will be an environment where an organization is more likely to achieve its objectives.

According to the model, the University of Mississippi administration exhibited a lack of coordinated communication and surrounded itself in an air of secrecy with the announcement that Colonel Reb would no longer represent Ole Miss athletics. University administrators also failed to include constituent feedback in making the decision. As a result the university constituencies felt isolated, excluded, and offended.

\section{Conclusion}

Using the issue management model to identity the issue and then communicate with various publics through information gathering and promotion allows organizations to better understand the different ways issues relate to organizational and member identity. Further, once organizations understand different frames, the organization can work to reshape these frames through a dialogue with multiple constituents. By soliciting feedback and actively engaging relevant publics, an organization can create a more effective solution to managing potentially dangerous issues, and can place itself in a better position to turn a possibly divisive issue into an opportunity for relationship building and developmental growth.

\section{Timeline 1: Colonel Reb issue at University of Mississippi in Summer/ Fall 2003}

May 19: Ole Miss athletics director Pete Boone announces that Colonel Reb, the 
mascot at the University of Mississippi who dresses the part of an eighteenthcentury gentleman, should no longer represent sports teams at the university. "It doesn't fit anything we do," says Boone (AP wire, <Sports Illustrated.com>)

June 19: Pete Boone announces that Colonel Reb will be in the Grove before football games, but will not be on the sidelines. Boone cites need for "champion's image" in ousting Colonel Reb. Boone says there has been talk of changing Colonel Reb for eight years. Ole Miss Assistant Vice Chancellor of University Relations, Jeff Alford, is caught off-guard, saying, "This is coming strictly from the athletic department. I don't know what kind of effect it is going to have, if any" (Daily Mississippian). The Daily Mississippian (the campus newspaper) releases an editorial lambasting the administration's mixed messages and closed-mouth policy regarding Colonel Reb. The editorial describes the alienation of students and alumni and the disconnection between different areas of campus regarding the mascot issue.

June 20: Chancellor Khayat reports that Colonel Reb is still an "official symbol" of Ole Miss, distinguishing Colonel Reb as an "athletic issue." AD Pete Boone explains that Colonel Reb "is not an athletic mascot, and does not represent anything athletic." A contest is suggested to replace the current mascot. Ticket sales remain on pace with 2002 (Daily Mississippian).

June 23: Alternative reasons for discarding Colonel Reb at sporting events begin to circulate. The Daily Mississippian speculates that the recruitment of student athletes may have been an influencing factor, as some players and coaches may associate Colonel Reb with racism, slavery, and the subjugation of blacks. No administrator is available for comment.
July 03: The Black Student Union issues an official statement on the debate over Colonel Reb. It reads, "We, the Black Student Union, agree that Colonel Reb should be changed to promote the progress of our University, our state and our nation." It continues, "we believe that the mascot should reflect common ideals, goals and the fighting spirit that has made our state a better place to live" (Daily Mississippian).

July 11: Alumni begin to voice opinions about the replacement of Colonel Reb at athletic events. Most are negative, citing the way the issue was handled, more than the issue itself. Chancellor Khayat releases a column in the Daily Mississippian, stating: (1) The University of Mississippi is and will remain the Rebels; (2) The song "Dixie" will remain in the song repertoire; (3) Colonel Reb is and will continue to be an official trademark of the university. $\mathrm{He}$ claims that race has no influence in the decision.

July 30: Pete Boone announces a nationwide contest to find a new mascot who "demonstrates a fighting spirit, exhibits independence, and challenges the status quo." The winner will receive a $\$ 5,000$ cash prize and will be announced in late September (Daily Mississippian). October 6: Speaking of the issue of race, Pete Boone tells the Commercial Appeal, "As a matter of fact I've got two letters on my desk right now that other coaches have written to athletes that we're recruiting trying to play this mascot issue against us."

October 10: Ole Miss ends its search for a new mascot citing a lack of interest in the two proposed replacements for Colonel Reb. The university received just 2,400 out of a possible 40,000 votes from students, faculty, alumni, ticket holders and athletic boosters who were eligible to 
vote. "It is clear from the responses received and from general public discussion that there is no community support for either of the proposed mascots," says Chancellor Robert Khayat. "Therefore, the matter is closed" (Baton Rouge Advocate).

\section{Timeline 2: Issues at University of Mississippi}

1848: The University of Mississippi opens its doors to 80 students.

1861: The university closes and most students leave to fight for Confederacy. They are termed the "University Greys."

1865: University of Mississippi reopens. 1896: Students publish the first yearbook and call it "Ole Miss." The name sticks to the school.

1936: The Ole Miss "Flood" becomes the Ole Miss "Rebels" after the name is chosen by 18 of 21 Southern sportswriters in a contest sponsored by the school newspaper.

1962: James Meredith commences to integrate higher education in Mississippi, and succeeds. Five men had already attempted to integrate higher education in Mississippi to no avail.

1979: Colonel Reb introduced as Ole Miss mascot, replacing a member of the student body chosen annually to dress as a Confederate soldier during games.

1983: Ole Miss Faculty and staff officially disassociate the school from the Confederate battle flag.

1987: University of Mississippi alumnus Ralph Eubanks writes an article in the Washington Post describing his experience at a socially and culturally segregated Ole Miss. The negative impact of Confederate flag and Colonel Reb on black students is mentioned in the article.

1991: The Ole Miss Alumni association disassociates from the Confederate flag. 1995: Robert C. Khayat becomes the 15th Chancellor of the University of Mississippi.

1997: The Ole Miss Student senate adopts a resolution urging students to refrain from waving the Confederate flag at Ole Miss athletic events. Fans largely adhere to the policy. Chancellor Khayat hires New York-based Burson-Marsteller to perform a study on Colonel Reb and other symbols at Ole Miss, citing the purpose of strengthening the academic reputation of the university.

2000: The University of Mississippi gains the legal right to ban spectators from waving Confederate flags at campus athletic events, according to the Fifth Circuit United States Court of Appeals. University of Mississippi officials suspend Alpha Tau Omega after a member costumed as a police officer points a gun at a man wearing blackface

2002: Chancellor Khayat speaks to the Daily Mississippian regarding the future of Colonel Reb: We are and will be Ole Miss. We are and will be the Rebels. We do and will continue to play "Dixie." Colonel Reb will be the mascot."

2003: Ole Miss Loyalty Foundation hires New York-based Phoenix Group to study Colonel Reb and other university symbols. Ole Miss announces Colonel Reb will no longer be on the sidelines of athletic events.

\section{Timeline 3: Relevant Issues around the} Country 1989: An article is released in the Chronicle of Higher Education advocating university image review, specifically mentioning costs, athletics scandals, and racial incidents. NAACP and other civil rights leaders demand Southern politicians make efforts to remove the Confederate flag and Confederate symbols from public grounds. 
1995: According to the Nerw York Times, Chancellor Khayat calls for a period of self-analysis at the University of Mississippi, citing that the symbols of Ole Miss may be hindering the university's chances of receiving a Phi Beta Kappa chapter. Khayat hires Burson-Marsteller to study the university's image. Burson, the firm's chairman and an Ole Miss grad, comments, "He's [Khayat] asking himself, 'What are the impediments to establishing credibility and status?' and our preliminary assessment shows that the race card always comes up. If it's playing an important part, I think we should get rid of some of the symbols, the most offensive ones" (New York Times).

1999: The NAACP passes a resolution rejecting the use of Native Americans and "all historically oppressed people and their cultural traditions" as sports mascots and symbols (Black Issues in Higher Education).

2002: Vanderbilt University announces plans to remove Confederate from Confederate Memorial Hall dormitory. 2003: Edgefield County (SC) residents and the NAACP protest Strom Thurmond High School's "Rebel" mascot. The mascot is almost identical to Ole Miss's Colonel Reb.

\section{References}

1. F. E. Everett, Jr. (1932), retrieved from <http:// olemisssports.collegesports.com/school-bio/ whyolemiss.html>, November 2004.

2. M. Sindelar (2003), "Colonel Reb mascot still University of Mississippi official symbol, Chancellor says," Daily Mississippian, June 20. Retrieved November 21, 2004 from <http://www.uwire.com>.

3. M. Atkins (2003), "Ole Miss may phase out Colonel Rebel mascot," Daily Mississippian, May 28. Retrieved November 21, 2004 from <http://www.uwire.com>.

4. “Ole Miss won't replace Colonel Reb," Baton Rough Advocate, October 10, 2003. Retrieved from <http:// proquest.umi.com>.

5. Atkins (2003), "Ole Miss may phase out Colonel Rebel mascot," op. cit.
6. Sindelar (2003). "Colonel Reb mascot still University of Mississippi official symbol," op. cit.

7. Ibid.

8. Atkins (2003), "Colonel Rebel could face termination," Daily Mississippian, May 28. Retrieved November 21, 2004 from <http://www.uwire.com>.

9. Ibid.

10. M. Sindelar (2003), "Black Student Union publicly supports Colonel Reb's ousting," Daily Mississippian, July 3. Retrieved November 21, 2004 from <http:// www.uwire.com>.

11. K. McKenzie (2003), “Ole Miss designs 'colonel' of future-reconstruction difficult so far," The Commercial Appeal, October 6. Retrieved November 18, 2004 from 〈http://proquest.umi.com〉.

12. Sindelar (2003). "Colonel Reb mascot still University of Mississippi official symbol," op. cit.

13. Editorial Board (2003), "And the fans were the last to know,” Daily Mississippian, June 19. Retrieved November 21, 2004 from <http://www.uwire.com>.

14. M. Atkins (2003), "Mascot change could cause diminishing funds," Daily Mississippian, July 11. Retrieved November 21, 2004 from <http:// www.uwire.com>.

15. T. C. Pauchant and I. I. Mitroff (1992), Transforming the Crisis-Prone Organization: Preventing Individual, Organizational, and Environmental Tragedies, JosseyBass, San Francisco, p. 15.

16. M. Seeger, T. Sellnow, and R. Ulmer (2000), "Public relations and crisis communication: Organizing and chaos," in R. L. Heath (Ed.), Handbook of Public Relations, Sage, Thousand Oaks, CA, pp. 155-65.

17. Ibid.

18. A. Gonzalez-Herrero and C. Pratt (1996), “An integrated symmetrical model for crisiscommunication management," Journal of Public Relations Research, 8, 2, pp. 79-105.

19. J. Burnett (1998). "A strategic approach to managing crises,” Public Relations Revierw, 24, 4, pp. 475-88.

20. Ibid.

21. Seeger, Sellnow, and Ulmer (2000), "Public relations and crisis communication," op. cit.

22. Ibid, p. 157

23. J. Dutton and M. Dukerich (1991), "Keeping an eye on the mirror: Image and identity in organizational adaptation," The Academy of Management Journal, 34, 3, pp. 517-54.

24. Seeger, Sellnow, and Ulmer (2000), "Public relations and crisis communication," op. cit.

25. Gonzalez-Herrero and Pratt (1996). "An integrated symmetrical model for crisis-communication management," op. cit.

26. Atkins (2003), "Ole Miss may phase out Colonel Rebel mascot," op. cit.

27. Burnett (1998), "A strategic approach to managing crises,” op cit.; D. Burkowitz, and K. Turnmire (1994), "Community relations and issues 
management: an issue orientation approach to segmenting publics," Journal of Public Relations Research, 6, 2, pp. 105-23.

28. Ibid.

29. G. Vasquez and M. Taylor (2000), "Research perspectives on 'the public'," in R. L. Heath (Ed.), Handbook of Public Relations, Sage, Thousand Oaks, CA, pp. 139-54.

30. Dutton and Dukerich (1991), "Keeping an eye on the mirror," op. cit., p. 520.

31. S. Albert and D. Whetten (1985), "Organizational identity,” in L. L. Lummings and B. M. Staw (Eds.), Research in Organizational Behavior, vol. 7, pp. 263-95.

32. Dutton and Dukerich (1991), "Keeping an eye on the mirror," op. cit.

33. M. Connolly (2000), "What's in a name? A historical look at Native American-related nicknames and symbols at three U.S. universities," Journal of Higher Education, 71, 5, pp. 515-47.

34. Spiegel, B. (1961), The Structure of Diffusion of Opinions in the Social Field. A Psychological Model of the Market. Bern and Stuttgart: Hans Huber, p. 29.

35. Dutton and Dukerich (1991). "Keeping an eye on the mirror," op. cit
36. Ibid.

37. S. Leitch, and D. Neilson (2000), "Bringing publics into public relations: New theoretical frameworks for practice," in R. L. Heath (Ed.), Handbook of Public Relations, Sage, Thousand Oaks, CA, pp. 12738.

38. G. Vasquez (1996), "Public relations as negotiation: An issue development perspective," Journal of Public Relations Research, 8, 1, pp. 57-77.

39. Leitch and Neilson, "Bringing publics into public relations," op. cit.

40. K. McKenzie (2003), 'Ole Miss designs 'Colonel' of future-reconstruction difficult so far," Commercial Appeal, October 6, p. A1

41. Connolly (2000), "What's in a name?," op. cit., p. 540.

42. Seeger, Sellnow, and Ulmer (2000), "Public relations and crisis communication,” op. cit.

43. Burnett (1998), "A strategic approach to managing crises,” op. cit.; Burkowitz and Turnmire (1994), "Community relations and issues management," op. cit.

44. Dutton and Dukerich (1991), "Keeping an eye on the mirror," op. cit. 